\title{
Chemical Sample Preparation for the Determination of Silicon-32 by Accelerator Mass-Spectrometry
}

\author{
By David Zimmermann and Hans R. von Gunten \\ Paul Scherrer Institut, CH-5232 Villigen PSI, Switzerland
}

(Received June 9, 1995; revised August 10, 1995)

\section{Silicon-32 / Dating / Accelerator mass-spectrometry}

\begin{abstract}
Silicon-32 is produced in very small concentrations by interactions of cosmic rays in the atmosphere. It can be used for nuclear dating purposes, but its measurement is very difficult. The recent availability of accelerator mass-spectrometry (AMS) may help to increase the sensitivity for detection of ${ }^{32} \mathrm{Si}$. We describe a chemical method which produces elemental silicon to be used in the ion source of an AMS-installation. The material containing $\mathrm{Si}$ is dissolved in HF. $\mathrm{SiF}_{4}$ is reduced to $\mathrm{SiH}_{4}$ which is thermally decomposed to elemental silicon. Elemental silicon, deposited on graphite discs, is, thus far, the most suitable material for ${ }^{32} \mathrm{Si}$ determinations by AMS, yielding the purest and highest ion currents of all tested materials. At present we can determine ${ }^{32} \mathrm{Si} / \mathrm{Si}_{\mathrm{tot}}$ ratios of about $10^{-13}$, and reach the same sensitivity as in radiochemical counting techniques.
\end{abstract}

\section{Introduction}

The ongoing concern about man-made climatic changes has enhanced the demand for accurate nuclear dating methods. These methods are used to assign time information to climatic parameters or to pollution of the past. Information on climate variations and air pollution is conserved in closed 'environmental archives' (e.g., glacier ice, aquatic sediments, peat, etc.). Well established dating methods depend, for instance, on ${ }^{210} \mathrm{~Pb}[1-3]$ or ${ }^{14} \mathrm{C}[4]$ as radioactive clocks. Whereas ${ }^{210} \mathrm{~Pb}$ can be used to date about the last 150 years, ${ }^{14} \mathrm{C}$ is suitable to establish ages of samples older than 1000 years. The time gap of several 100 years between the ranges of the half-lives of ${ }^{210} \mathrm{~Pb}$ and ${ }^{14} \mathrm{C}$ would be ideally filled by applications of ${ }^{32} \mathrm{Si}\left(T_{1 / 2} \sim 130 \mathrm{y}\right)$. This radionuclide could be used in the time range of $\sim 100-1000$ years before the present, and could help to date specimen of the Middle Ages and of the 'Little Ice Age'. An accurate dating of samples representing these time periods is important for an improvement of our understanding of reasons for temperature and climatic changes.

Silicon-32 is produced in the upper atmosphere by interactions (spallation) of cosmic ray particles with argon $\left\{\right.$ e.g., $\left.{ }^{40} \mathrm{Ar}(\mathrm{p}, 2 \alpha \mathrm{p})^{32} \mathrm{Si}\right\}$, and enters the terrestrial environment by wet and dry fall-out. Unfortunately, the atmospheric production rate is only about 1.6 $\times 10^{-4}$ atoms $/ \mathrm{cm}^{2} \mathrm{~s}$ [5] corresponding to a global equilibrium amount of about $2 \mathrm{~kg}{ }^{32} \mathrm{Si}$. Because stable silicon is very abundant in the lithosphere and hydrosphere, the ${ }^{32} \mathrm{Si} / \mathrm{Si}_{\text {tot }}$ ratios are extremely small (see Table 1) and, therefore, a determination is very difficult to perform and time consuming. For instance, ton(s) of material must be processed for a radioactivity measurement of ${ }^{32} \mathrm{Si}$ via its decay product ${ }^{32} \mathrm{P}$. These large samples are difficult to handle, and lead to a very poor resolution in space and time. With the recent availability of the very sensitive accelerator massspectrometry (AMS), it should eventually be possible to reduce the sample size for a determination of ${ }^{32} \mathrm{Si}$.

A further problem for an unambiguous application of ${ }^{32} \mathrm{Si}$ as dating nuclide arises from the half-life which is still not known with the desired accuracy. Older half-life values covered a range between 80 and 700 years [10-13]. Table 2 gives a summary of the more recent results. There is still a considerable scatter in the half-lives, but the data suggest a 'center of gravity' at about 130 years, obtained by averaging the more recent results. The value of 130 years is in agreement with the results of careful redeterminations by two fully independent methods and widely varying materials for the production of ${ }^{32} \mathrm{Si}[20,21,23]$.

For an application of ${ }^{32} \mathrm{Si}$ in AMS, the chemical and physical forms of the sample in the ion source are of prime importance. For the redetermination of the half-life of ${ }^{32} \mathrm{Si}[20,21]$, samples of $\mathrm{K}_{2} \mathrm{SiF}_{6}$ enriched in ${ }^{32} \mathrm{Si}\left({ }^{32} \mathrm{Si} / \mathrm{Si}_{\text {tot }} \approx 10^{-8}\right)$ were mixed with tantalum powder and were pressed into a hole in the target holders of the sputter ion source of the AMS. However, in order to detect ${ }^{32} \mathrm{Si}$ in natural samples, the sensitivity must be increased by several orders of magnitude. Improved forms of silicon in the ion source may contrib-

Table 1. Ratios of ${ }^{32} \mathrm{Si} / \mathrm{Si}_{\mathrm{tor}}$ in water and snow samples

\begin{tabular}{lcc}
\hline Sample & ${ }^{32} \mathrm{Si} / \mathrm{Si}_{\text {tot }}$ & $\begin{array}{l}\text { Refer- } \\
\text { ence }\end{array}$ \\
\hline River water & $1.5 \times 10^{-16}-4.9 \times 10^{-17}$ & {$[6]$} \\
Lake water & $1.2 \times 10^{-16}-5.1 \times 10^{-17}$ & {$[6]$} \\
Groundwater & $6.9 \times 10^{-17}-9.8 \times 10^{-18}$ & {$[6]$} \\
Ocean water: & & \\
$\quad$ Surface (0-150 m) & $9.7 \times 10^{-16}-2.5 \times 10^{-16}$ & {$[6]$} \\
$\quad$ Depth (>1000 m) & $2.0 \times 10^{-16}-5.1 \times 10^{-17}$ & {$[6]$} \\
Rain water & $1.3 \times 10^{-14}-6.2 \times 10^{-16}$ & {$[7]$} \\
Ice, glacier (Kaschmir, India) & $4.2 \times 10^{-15}-4.8 \times 10^{-17}$ & {$[8]$} \\
Snow (Jungfraujoch, & & \\
$\quad$ Switzerland) & $1.7 \times 10^{-15}-2.5 \times 10^{-17}$ & {$[9]$} \\
\hline
\end{tabular}


Table 2. Literature values of the half-life of ${ }^{32} \mathrm{Si}$. The more recent values converge at about 130 years

\begin{tabular}{ccllr}
\hline $\begin{array}{c}\text { Half-life } \\
\text { (years) }\end{array}$ & $\begin{array}{c}\text { Year of } \\
\text { publication }\end{array}$ & \multicolumn{1}{c}{ Method } & \multicolumn{1}{c}{ Comments } & Reference \\
\hline $330 \pm 40$ & 1973 & Drill core, ice Greenland & Decrease of ${ }^{32}$ Si with depth & {$[14]$} \\
222,277 & 1980 & Drill core, ice Greenland & Decrease of ${ }^{32}$ Si with depth & {$[15]$} \\
$276 \pm 32$ & 1980 & Drill core, Ocean sediments & Decrease of ${ }^{32}$ Si with depth & {$[15]$} \\
$217 \pm 29$ & 1983 & Drill core, Ocean sediments & Decrease of ${ }^{32}$ Si with depth & {$[16]$} \\
$108 \pm 18$ & 1980 & AMS & & {$[17]$} \\
$101 \pm 18$ & 1980 & AMS & $\beta^{-}$counting, instabilities & {$[18]$} \\
$172 \pm 4$ & 1986 & Radioactive decay (4 years) & two different ${ }^{32}$ Si samples & {$[19]$} \\
$133 \pm 9$ & 1990 & AMS & & {$[20,21]$} \\
$162 \pm 12$ & 1991 & AMS & & {$[22]$} \\
$132 \pm 12$ & 1993 & Ion implanted target & & {$[23]$} \\
\hline
\end{tabular}

ute to this goal by giving high and more stable ion currents. In addition, ion source materials of very high chemical purity are required to keep contamination by interfering nuclides of the isobar $32\left(\right.$ e.g., ${ }^{32} \mathrm{~S}$ ) as low as possible. Test measurements have shown that semiconductor silicon ion sources contained less sulfur and yielded about ten times higher ion currents than the $\mathrm{K}_{2} \mathrm{SiF}_{6}$ sources. Therefore, a chemical procedure was developed for the transformation of small samples of silicon compounds into elemental silicon which can be used in the AMS. Considerable improvements were also made at the AMS installation itself (e.g., addition of a gas filled magnet to the beam line to reduce drastically disturbances by sulfur-32 [24]); these improvements have been described elsewhere [25].

\section{Experimental}

Vacuum techniques in an apparatus built of stainless steel and quartz are used throughout the chemical procedure. The vacuum is produced by an oil rotary pump. A schematic drawing of the vacuum apparatus is shown in Figure 1. The procedure consists of three main steps which are described separately.

\section{Production of $\mathrm{SiF}_{4}$}

Enriched silicon samples (e.g., standards of $\mathrm{BaSiF}_{6}$ or $\mathrm{K}_{2} \mathrm{SiF}_{6}$ containing added ${ }^{32} \mathrm{Si}$ ) are decomposed in the furnace tube $A$ of the apparatus (see Fig. 1) at $750^{\circ} \mathrm{C}$. The evolving $\mathrm{SiF}_{4}$ is collected immediately in trap $\mathbf{B}$ (valve 1 closed) which is cooled by liquid nitrogen. If natural samples are to be investigated, $\mathrm{SiF}_{4}$ is generated during the dissolution of the sample (in a reaction chamber added of the apparatus) with $\mathrm{HF} / \mathrm{HClO}{ }_{4}$ or $\mathrm{HF} / \mathrm{H}_{2} \mathrm{SO}_{4}$. It is transferred through tube $\mathrm{A}$ and collected in cold trap B. Water and acid vapors are condensed in a cold trap before entering the main apparatus.

\section{Reduction of $\mathrm{SiF}_{4}$ with $\mathrm{LiAlH}_{4}$}

About $300 \mathrm{mg} \mathrm{LiAlH}_{4}$ in $5-10 \mathrm{ml}$ ether are introduced to the removable trap $\mathbf{C}$ (Fig. 1) which is cool-

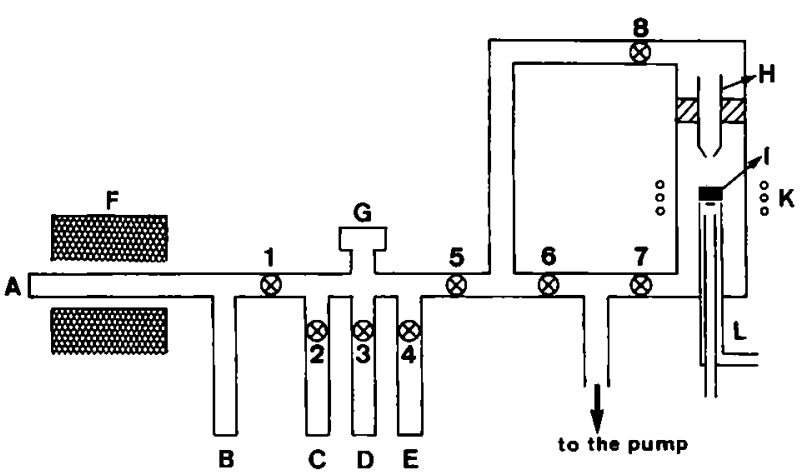

Fig. 1. Schematic representation of the vacuum apparatus. The apparatus is built from stainless steel tubes, except the inductively heated quartz reaction chamber on the right hand side of the drawing. A: stainless steel tube; B-E: cold traps; F: tube furnace; G: piezoelectric pressure transducer; H: capillary; I: sample disc; K: heating coil; L: water cooled copper rod; 1-8: valves.

ed with liquid nitrogen $\left(-196^{\circ} \mathrm{C}\right)$. Trap B is warmed and kept at $-78^{\circ} \mathrm{C}$ (acetone/dry ice mixture), and $\mathrm{SiF}_{4}$ is transferred and condensed into reaction tube $\mathrm{C}$ (valves 3,4,5 closed). While the reactants are slowly and carefully brought to room temperature (valve 2 closed), the formation of $\mathrm{SiH}_{4}$ takes place ( one hour). Trap $\mathrm{C}$ is then again cooled to $-196^{\circ} \mathrm{C}$. Noncondensable gases (e.g., $\mathrm{H}_{2}$ ) are pumped off (valves 2,5,6 open). The liquid nitrogen of trap $\mathbf{C}$ is replaced by n-pentane/liquid $\mathrm{N}_{2}\left(-130^{\circ} \mathrm{C}\right)$, and $\mathrm{SiH}_{4}$ is condensed into trap $\mathbf{D}$ which contains dry benzene at $-196{ }^{\circ} \mathrm{C}$. Trap D is warmed to room temperature (valve 3 closed) and allowed to stand for about one hour, the time necessary for the absorption and dissolution of ether vapors in the benzene [26]. After cooling trap $\mathbf{D}$ to $-130^{\circ} \mathrm{C}, \mathrm{SiH}_{4}$ is collected in trap $\mathbf{E}$ which is cooled by liquid nitrogen. The pressures and pressure changes are controlled with the piezoelectric pressure transducer $\mathbf{G}$.

\section{Decomposition of $\mathrm{SiH}_{4}$}

With valve 6 closed (and valve 8 open), and gently warming trap $\mathrm{E}, \mathrm{SiH}_{4}$ is transferred into the decomposition chamber. The flow of $\mathrm{SiF}_{4}$ is controlled with 


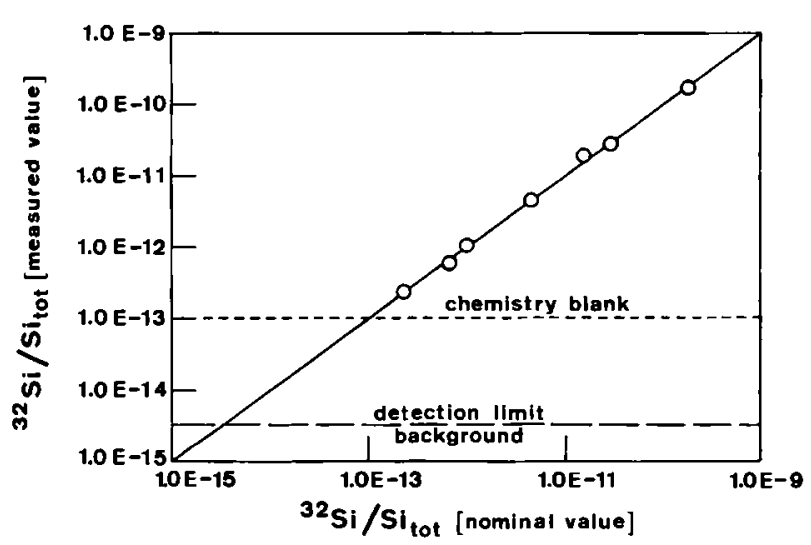

Fig. 2. Measured ${ }^{32} \mathrm{Si} / \mathrm{Si}_{\text {tot }}$ ratios of standard samples versus their nominal values (Fig. 2 modified after [25], reproduction permitted by Elsevier Science B.V., Amsterdam, The Netherlands). The measured ratios are normalized to a standard sample with a ${ }^{32} \mathrm{Si}$ / $\mathrm{Si}_{\text {tot }}$ ratio of $1.75 \times 10^{-10}$. The presently reached detection limit (background value) for a ${ }^{32} \mathrm{Si} / \mathrm{Si}_{\text {rot }}$ ratio of $3.3 \times 10^{-15}$ was obtained with ultra-pure semiconductor silicon in the ion source of the Zürich AMS installation (no chemical processing). The dotted line for the chemistry blank $\left({ }^{32} \mathrm{Si} / \mathrm{Si}_{\mathrm{tot}} \sim 10^{-13}\right)$ represents the lowest ratios obtained so far with elemental silicon samples (deposited on graphite discs) which were prepared from $\mathrm{BaSiF}_{6}$ or $\mathrm{SiH}_{4}$ by the vacuum technique described in the text and in Fig. 1 .

valve 5. The decomposition chamber consists of a quartz tube in which a sample disc (tantalum or graphite \{Ultra Carbon Corporation, Bay City, Michigan, USA \}, $10 \mathrm{~mm}$ diameter, $1 \mathrm{~mm}$ thick) is placed on top of a water-cooled copper rod. The sample disc is inductively heated from the outside of the quartz tube to $700-800^{\circ} \mathrm{C}$. $\mathrm{SiH}_{4}$ is directed through a capillary to the hot disc, where it decomposes into elemental silicon and $\mathrm{H}_{2}$. While elemental silicon is deposited on the disc at a rate of $\sim 1 \mathrm{mg}$ Si per $20-30 \mathrm{~min}, \mathrm{H}_{2}$ is continuously pumped off.

\section{Results and discussion}

Synthetic samples containing varying trace amounts of ${ }^{32} \mathrm{Si}$ have been used up to now. If $\mathrm{BaSiF}_{6}$ is the starting material, the yields of elemental silicon were about $60 \%$. Silicon deposits on tantalum as well as on graphite discs were suitable for use in the sputter ion source of the AMS installation. However, the deposits on the graphite discs supplied a more constant and higher ion beam. Moreover, the deposits on graphite contained smaller sulfur contamination, and were therefore chosen for the further development of the method.

In Figure 2 the results of standard sample measurements at the Zürich AMS installation are presented. The relation between the measured ${ }^{32} \mathrm{Si} / \mathrm{Si}_{\text {tot }}$ ratios and their nominal values is linear and, hence the proof of a very good agreement. The standards were obtained by addition of the appropriate amounts of inactive $\mathrm{BaSiF}_{6}$ (or $\mathrm{SiH}_{4}$ ) to a well characterized sample with a ${ }^{32} \mathrm{Si} / \mathrm{Si}_{\text {tot }}$ ratio of $1.75 \times 10^{-10}$. These materials were then processed by the procedure described above.

Figure 2 also shows the present detection limit (background) of the method, namely a ${ }^{32} \mathrm{Si} / \mathrm{Si}_{\text {tot }}$ ratio of $3.3 \times 10^{-15}$, obtained with ultra-pure silicon semiconductor materials used in the ion source of the AMS. This limit approaches closely a ratio necessary to measure natural silicon samples for dating purposes (see Table 1). In order to reach this very low detection limit, a gas-filled magnet was used in the beam line of the Zürich AMS [25].

Unfortunately, there exist still problems with the chemically processed samples. Thus far it was not possible to reach blank values below a ${ }^{32} \mathrm{Si} / \mathrm{Si}_{\text {tor }}$ ratio of $\sim 10^{-13}$. The blank samples were obtained from inactive $\mathrm{BaSiF}_{6}$ and from commercially available $\mathrm{SiH}_{4}$ which were processed in the vacuum apparatus. Furthermore, there were considerable variations in the blank values. With the present blank values, the sensitivity of the AMS method is not better than that of the radiochemical counting technique. We suspect that the blank problem might have been caused by remaining ${ }^{32} \mathrm{Si}$ in the vacuum apparatus, since up to now the same apparatus (Fig. 1) was used for enriched as well as low level samples. Even very elaborate and carefully applied cleaning procedures may not have completely decontaminated the apparatus from ${ }^{32} \mathrm{Si}$. Further blank tests, and later, attempts to measure ${ }^{32} \mathrm{Si}$ in natural samples will, therefore, be performed in an improved new and clean apparatus which was never used for the preparation of samples with elevated concentrations of ${ }^{32} \mathrm{Si}$. High blanks could also be the result of traces of ${ }^{32} \mathrm{Si}$ in the used chemicals. In order to exclude this possibility, a chemistry test with ultra-pure semiconductor silicon as starting material will be performed. Furthermore graphite discs (for the deposition of $\mathrm{Si}$ ) from other suppliers will be tested. Meanwhile, modifications were also made at the AMS installation in order to increase the beam current and the efficiency of the output of the ion source [25, 27].

In conclusion, we can state that considerable progress has been made in the development of a method for measurement of ${ }^{32} \mathrm{Si}$ by accelerator mass-spectrometry. The presently attained status looks promising for future applications of this method to dating problems in a time range not accessible by other methods. But still, there remain problems (see above) to be resolved before accelerator mass-spectrometry of ${ }^{32} \mathrm{Si}$ can be used for measurement and dating of natural samples.

\section{Acknowledgments}

The authors acknowledge the help, measurements and discussions by the Zürich AMS crew, namely by G. Bonani, H. J. Hofmann, P. W. Kubik, M. Suter, H.-A. Synal, W. Wölfli and U. Zoppi, and the constructive criticism of an anonymous reviewer. The work was partly supported by the Swiss National Science Foundation.

\section{Literature}

1. Goldberg, E. D.: Radioactive Dating, IAEA STI/PUB/68: 121-131, Vienna 1963. 
2. Krishnaswami, S., Lal, D., Martin, J. M., Meybeck, M.: Earth Planet. Sci. Lett. 11, 407-414 (1971).

3. von Gunten, H. R., Moser, R. N.: J. Paleolimnol. 9, 161178 (1993).

4. Libby, W. F.: Radiocarbon Dating, University of Chicago Press, Chicago, IL., 1955.

5. Roth, E., Poty, B. (eds.): Nuclear Methods of Dating, Kluwer Academic Publishers, Dordrecht 1989.

6. Lal, D., Somayajulu, B. L. K.: Tectonophysics 105, 383397 (1984).

7. Franke, T., Fröhlich, K., Gellermann, R., Herbert, D. : J. Radioanal. Nucl. Chem. Lett. 103, 11-17 (1986).

8. Nijampurkar, V. N., Bhandari, N., Vohra, C. P., Krishnan, V.: J. Glaciol. 28, 91-105 (1982).

9. Parrat, Y.: Personal communication.

10. Turkevich, A., Samuels, A.: Phys. Rev. 94, 364 (1954).

11. Geithof, D.: Radiochim. Acta 1, 3-6 (1962)

12. Honda, M., Lal, D.: Nucl. Phys. 51, 363-368 (1964).

13. Jantsch, K.: Kernenergie 10, 89-91 (1967).

14. Clausen, H. B.: J. Glaciol. 12, 411-416 (1973).

15. DeMaster, D. J.: Earth Planet. Sci. Lett. 61, 257-271 (1982).

16. Cumming, J. B.: Radiochem. Radioanal. Lett. 58, 297-306 (1983).

17. Elmore, D., Anantaraman, N., Fulbright, H. W., Gove, H. E., Hans, H. S., Nishiizumi, K., Murell, M. T., Honda, M.: Phys. Rev. Lett. 45, 589-592 (1980).
18. Kutschera, W., Henning, W., Paul, M., Smither, R. K., Stephenson, E. J., Yntema, J. L., Alburger, D. E., Cumming, J. B., Harbottle, G.: Phys. Rev. Lett. 45, 592-596 (1980).

19. Alburger, D. E., Harbottle, G., Norton, E. F.: Earth Planet. Sci. Lett. 78, 168-176 (1986)

20. Zimmermann, D.: Neubestimmung der Halbwertszeiten von ${ }^{10} \mathrm{Be}$ und ${ }^{32} \mathrm{Si}$. Ph.D.-Thesis, Universität Bern, Switzerland 1991.

21. Hofmann, H. J., Bonani, G., Suter, M., Wölfli, W., Zimmermann, D., von Gunten, H. R.: Nucl. Instr. Meth. Phys. Res. B52, 544-551 (1990).

22. Thomsen, M. S., Heinemeier, J., Hornshøj, P., Nielsen, H. L., Rud, N.: Nucl. Phys. A534, 327-338 (1991).

23. Chen, Y., Kashy, E., Bazin, D., Benenson, W., Morissey, D. J., Orr, N. A., Sherrill, B. M., Winger, J. A., Young, B., Yurkon, J.: Phys. Rev. C47, 1462-1465 (1993).

24. Paul, M.: Nucl. Instr. Meth. Phys. Res. B52, 315-321 (1990).

25. Zoppi, U., Kubik, P. W., Suter, M., Synal, H.-A., von Gunten, H. R., Zimmermann, D.: Nucl. Instr. Meth. Phys. Res. B92, 142-145 (1994).

26. Padma, D. K., Suresh, B. S., Vasudevamurthy, A. R.: J. Fluorine Chem. 14, 327-329 (1979).

27. Niklaus, T.: Ph.D. Thesis, Diss. ETH no. 10065, Eidg. Technische Hochschule, Zürich, Switzerland 1993. 